\title{
The fate of banded iron formations in the deep mantle: Oxide reduction kinetics at high pressure
}

\author{
JEMILA EDMOND $^{1}$, JAMES VAN ORMAN ${ }^{2}$
}

${ }^{1}$ Case Western Reserve University, Department of Earth, Environmental and Planetary Sciences, Cleveland, $\mathrm{OH}$, USA (jxe165@case.edu).

${ }^{2}$ Case Western Reserve University, Department of Earth, Environmental and Planetary Sciences, Cleveland, $\mathrm{OH}$, USA(jav12@case.edu).

Banded Iron Formations (BIFs), sedimentary units composed of thin layers of iron oxides and silica, were prolific marine deposits early in Earth's history and likely experienced extensive subduction into the mantle. The mantle becomes significantly more reducing with increasing depth, with iron metal becoming stable at pressures above $\sim 8 \mathrm{GPa}$. During subduction, the nearly pure iron oxides within BIFs may progressively transform to more reduced minerals, ultimately producing iron metal in the deep mantle. Progressive reduction of BIFs could therefore have significant implications for deep Earth structure and dynamics. A metallic phase may be a significant constituent of the dense, large low shear velocity provinces (LLSVPs) in Earth's deep mantle. Reduction of BIFs also may have the potential to provide large bodies of metal in the mantle that could drop into the core, and provide a substrate for nucleation of Earth's inner core.

A critical question is how quickly iron oxides transform to metal under deep mantle conditions. At atmospheric pressure, reduction of iron oxides is rapid, enabled by the formation of a permeable pore network that enhances the transport of $\mathrm{O}_{2}$. We will present experimental results on iron oxide reduction kinetics at high pressures relevant to the deep mantle, where pore formation is suppressed. Preliminary results at $8 \mathrm{GPa}$ and $1400{ }^{\circ} \mathrm{C}$ indicate that the transformation of wüstite $\left(\mathrm{Fe}_{1-\mathrm{x}} \mathrm{O}\right)$ to metal under reducing conditions is much slower than at $1 \mathrm{~atm}$, but rapid enough to produce significant metal on geological timescales. 